\title{
MODIFIED MAGNETIC CHITOSAN FOR METHYLENE BLUE ADSORPTION
}

\author{
Haya Fathana ${ }^{1}$, Rahmi ${ }^{2, \bigotimes}$, Susilawati ${ }^{2}$, Muhammad Adlim ${ }^{1,3}$ and Surya Lubis ${ }^{2}$ \\ ${ }^{1}$ Graduate School of Mathematics and Applied Sciences, Universitas Syiah Kuala, Banda Aceh \\ 23111, Indonesia \\ ${ }^{2}$ Department of Chemistry, Faculty of Mathematics and Natural Sciences, Universitas Syiah \\ Kuala, Banda Aceh-23111, Indonesia \\ ${ }^{3}$ Department of Chemistry Education, Faculty of Teacher Training and Education, Universitas \\ Syiah Kuala, Banda Aceh-23111, Indonesia \\ ${ }^{\square}$ Corresponding Author : rahmi@fmipa.unsyiah.ac.id
}

\begin{abstract}
Sulfonated magnetic crosslinked chitosan had been prepared and applied for methylene blue adsorption from an aqueous solution. The characteristics of sulfonated magnetic crosslinked chitosan were studied with Scanning Electron Microscope (SEM), Fourier Transform Infrared (FT-IR) and X-Ray Diffraction (XRD). SEM images exhibit the structure of sulfonated magnetic crosslinked chitosan with a rougher surface than pure chitosan. The spectra of FT-IR suggest the presence of sulfonate group, Fe-O group and shifted wavenumber for amine and hydroxyl groups in chitosan, associated with the success of the preparation of sulfonated magnetic cross-linked chitosan. As an addition to the modified characteristics, the crystallinity of sulfonated magnetic crosslinked chitosan is observed by XRD to have a decline. The adsorption capacity of sulfonated magnetic crosslinked chitosan is found to be higher than the of pure chitosan. According to the isotherm studies, the methylene blue adsorption fits the Langmuir model $\left(\mathrm{R}^{2}=0.979\right)$ with qe $=28.57 \mathrm{mg} / \mathrm{g}$
\end{abstract}

Keywords: Adsorbent, $\mathrm{Fe}_{3} \mathrm{O}_{4}$, Chitosan, Methylene Blue, Sulfonation

RASĀYAN J. Chem., Vol. 14, No.4, 2021

\section{INTRODUCTION}

Industrial development in Indonesia is having rapid growth in these recent years. As the consequence, more wastewater is released from various industrial processes to the environment. ${ }^{1}$ Dye wastewater is known to be one of the major contributions to the water pollution, released from textile industries. One of the most commonly used dyes in textile industries is methylene blue. The presence of methylene blue in the aquatic environment, even in low concentrations $(1 \mathrm{ppm})$ can adversely affect the process of photosynthesis of the aquatic plants by inhibiting the sunlight transition. ${ }^{2}$ At the end of the day, it will disrupt the lives of the other aquatic organisms.

To solve the problem, adsorption can be used to effectively remove methylene blue from industrial wastewater disposal. Several adsorbents that have been reported are activated charcoal, silica ${ }^{3}$, eggshells, shells ${ }^{4}$, and chitosan. ${ }^{5}$ Chitosan is a biopolymer that has biodegradability and can be used as an adsorbent to remove methylene blue. ${ }^{6}$ Nevertheless, chitosan has weak chemical properties, such as being soluble in organic acid solvents. However, it can be overcome by crosslinking with crosslinking agents ${ }^{7}$ such as polyethylene glycol diglycidyl ether (PEDGE). Our previous work has prepared PEDGE crosslinked chitosan/activated carbon composite film for $\mathrm{Cd}^{+2}$ removal and the results obtained that the crosslinking of composites can improve the mechanical properties of composites. ${ }^{8}$ Modification can also be carried out to improve the chemical properties of chitosan, for instance by sulfonation. ${ }^{9}$ Based on our earlier report, sulfonation of chitosan using $\mathrm{Na}_{2} \mathrm{SO}_{3}$ can increase the adsorption efficiency of chitosan due to the presence of sulfonate groups. ${ }^{10}$

Based on the above information, it is necessary to research the preparation of adsorbent materials that can be used for methylene blue adsorption from industrial wastewater. To obtain adsorbents with high adsorption capacity, in this research, we had modified chitosan by introducing sulfonate groups through

Rasayan J. Chem., 14(4), 2292-2297(2021)

http://doi.org/10.31788/RJC.2021.1445944

This work is licensed under a CC BY 4.0 license. 


\section{RASĀYAN J. Chem.}

Vol. 14 | No. 4 |2292-2297| October- December | 2021

sulfonation, followed by crosslinking with PEDGE and intercalation with $\mathrm{Fe}_{3} \mathrm{O}_{4}$ prepared from Syiah Kuala Beach iron sand.

\section{EXPERIMENTAL}

\section{Material}

Chitosan has been obtained from Tokyo Chemical Industry Co., Ltd. Japan (with 75.0-85.0\% deacetylation degree, Manufactured from shrimp shell). To prepare $\mathrm{Fe}_{3} \mathrm{O}_{4}$, we have used iron sand from Syiah Kuala Beach, Aceh Province. Other materials include $\mathrm{HCl}$, ammonia, acetic acid, $\mathrm{NaOH}, \mathrm{H}_{2} \mathrm{SO}_{4}$, methylene blue, $\mathrm{NaNO}_{2}$ and $\mathrm{NaHSO}_{3}$ were obtained from Merck, Germany. Distilled water was obtained from the Department of Chemistry, Faculty of Mathematics and Natural Sciences, Universitas Syiah Kuala, Banda Aceh.

\section{Isolation of $\mathrm{Fe}_{3} \mathrm{O}_{4}$ particles}

$\mathrm{Fe}_{3} \mathrm{O}_{4}$ was isolated with coprecipitation, where the iron sand $30 \mathrm{~g}$ was firstly dissolved in $100 \mathrm{~mL} \mathrm{HCl}$ $12.07 \mathrm{M}$ then stirred for 30 minutes at $70^{\circ} \mathrm{C}$ and $250 \mathrm{rpm}$. Afterward, it was filtered, and the filtrate was collected. Ammonia was added slowly to the obtained filtrate, and the mixture was stirred for another 30 minutes at $70^{\circ} \mathrm{C}, \mathrm{pH} 6$, and $250 \mathrm{rpm}$. Subsequently, it was washed repeatedly using distilled water to reach $\mathrm{pH} 7$ and it was filtered then dried for 10 hours in the oven at $70^{\circ} \mathrm{C} .{ }^{11}$

\section{Preparation of Sulfonated Magnetic Chitosan}

Sulfonated chitosan is prepared by soaking the chitosan $(0.35 \mathrm{~g})$ into sulfonation agents for 24 hours. It was neutralized with distilled water and dried in oven at $40^{\circ} \mathrm{C}$ for 7 hours, sequentially ${ }^{10} .0 .25 \mathrm{~g}$ sulfonated chitosan was dissolved with $20 \mathrm{~mL}$ acetic acid $2 \%$ then stirred for 2 hours at $250 \mathrm{rpm}$. Polyethylene Glycol Diglycidyl Ether (PEDGE) as a crosslinking agent was then added to the mixture with various compositions and stirred for another 2 hours. After that, $0.5 \mathrm{~g} \mathrm{Fe}_{3} \mathrm{O}_{4}$ was added and stirred for another 1 hour. Then, the mixture was poured into a syringe and dropped into $\mathrm{NaOH} 3 \mathrm{M}$ to obtain the microspheres. It was sequentially neutralized using distilled water. Then filtered and dried in an oven at $40^{\circ} \mathrm{C}$ for 14 hours.

\section{Methylene Blue Adsorption Process}

As many as $0.1 \mathrm{~g}$ sulfonated magnetic PEDGE crosslinked chitosan was added into $10 \mathrm{~mL}$ of methylene blue with initial concentration variations of $20 \mathrm{ppm}, 40 \mathrm{ppm}, 60 \mathrm{ppm}, 80 \mathrm{ppm}$, and $100 \mathrm{ppm}$. It was placed on a shaker at $250 \mathrm{rpm}$ for 30 minutes. Adsorbents were then separated with the help of permanent magnets. The final concentration of methylene blue was determined with a spectrophotometer UV-Vis at the maximum wavelength. The $\mathrm{Q}_{\max }$ value was calculated with the Langmuir equation.

\section{Regeneration Study}

The used sulfonated magnetic chitosan was added into $\mathrm{H}_{2} \mathrm{SO}_{4} 3 \mathrm{M}$ solution for 30 minutes. The adsorbent was then washed with distilled water to reach neutral $\mathrm{pH}$. The adsorbent is used repeatedly for the adsorption process.

\section{Characterization}

\section{RESULTS AND DISCUSSION}

Sulfonated magnetic crosslinked chitosan, which had been prepared previously, was then characterized with SEM (Scanning Electron Microscopy), FT-IR (Fourier Transform-Red Spectroscopy), and XRD (XRay Diffraction).

Based on Fig.-1, it can be seen that the SEM images provide information about the surface morphology of chitosan and sulfonated magnetic chitosan crosslinked PEDGE. It is found that the chitosan microsphere has a smoother surface than the sulfonated magnetic cross-linked chitosan. It indicates a fine distribution of the filler $\left(\mathrm{Fe}_{3} \mathrm{O}_{4}\right)$ in the sulfonated chitosan matrix. It is also found that the sulfonated magnetic chitosan, which has been crosslinked by PEDGE has a more rounded shape and smaller particle size, suggesting an increase in the surface area and the rougher surface can contribute to higher adsorption capacity. ${ }^{12}$ Based on the results of FT-IR analysis in Fig.-2, some functional groups can be observed. The chitosan microsphere gives an IR spectrum that shows the presence of $\mathrm{OH}$ group at $3427.51 \mathrm{~cm}^{-1}$ and NH 
group at $1633.71 \mathrm{~cm}^{-1}$. A shifted vibrational wavenumber of $\mathrm{NH}$ can be observed on the IR spectrum given by the sulfonated magnetic PEDGE crosslinked chitosan, which was initially at $1633.71 \mathrm{~cm}^{-1}$ to $1631.78 \mathrm{~cm}^{-1}$, indicating the successful crosslinking, where the NH groups on the chitosan reacted with the $\mathrm{CH}$ groups on the PEDGE ${ }^{13}$. The IR spectrum of the sulfonated magnetic PEDGE crosslinked chitosan exhibits the presence of Fe-O group at $580.57 \mathrm{~cm}^{-1}$. In the IR spectrum of sulfonated magnetic crosslinked chitosan, the $\mathrm{OH}$ vibrational wavenumber has shifted to a lower number, from $3427.51 \mathrm{~cm}^{-1}$ to $3406.29 \mathrm{~cm}^{-1}$. The broadened peak of $\mathrm{OH}$ vibrational area is ascribed to the presence of hydrogen bonds formed between the hydrogen atom, which is attached to the oxygen atom in the sulfate groups. The shift in the $\mathrm{OH}$ wavenumber region is due to the ability of the oxygen atoms to attract electrons so that the $\mathrm{OH}$ bond would be weaker in the sulfate groups compared to hydroxyl groups.

The XRD patterns in Fig.-3 show a sharper diffractogram peak in the composite without the addition of $\mathrm{Fe}_{3} \mathrm{O}_{4}$ and crosslinking agent, which is associated with the high crystallinity of the chitosan. As an addition, The typical diffractogram of chitosan at $2 \theta=19.5^{\circ}$ can also be observed ${ }^{14}$. Diffractogram peaks in the sulfonated magnetic chitosan show a typical angle of $\mathrm{Fe}_{3} \mathrm{O}_{4}$, at $2 \theta=35.42^{\circ}$, indicating that $\mathrm{Fe}_{3} \mathrm{O}_{4}$ was successfully introduced with the preparation procedure.
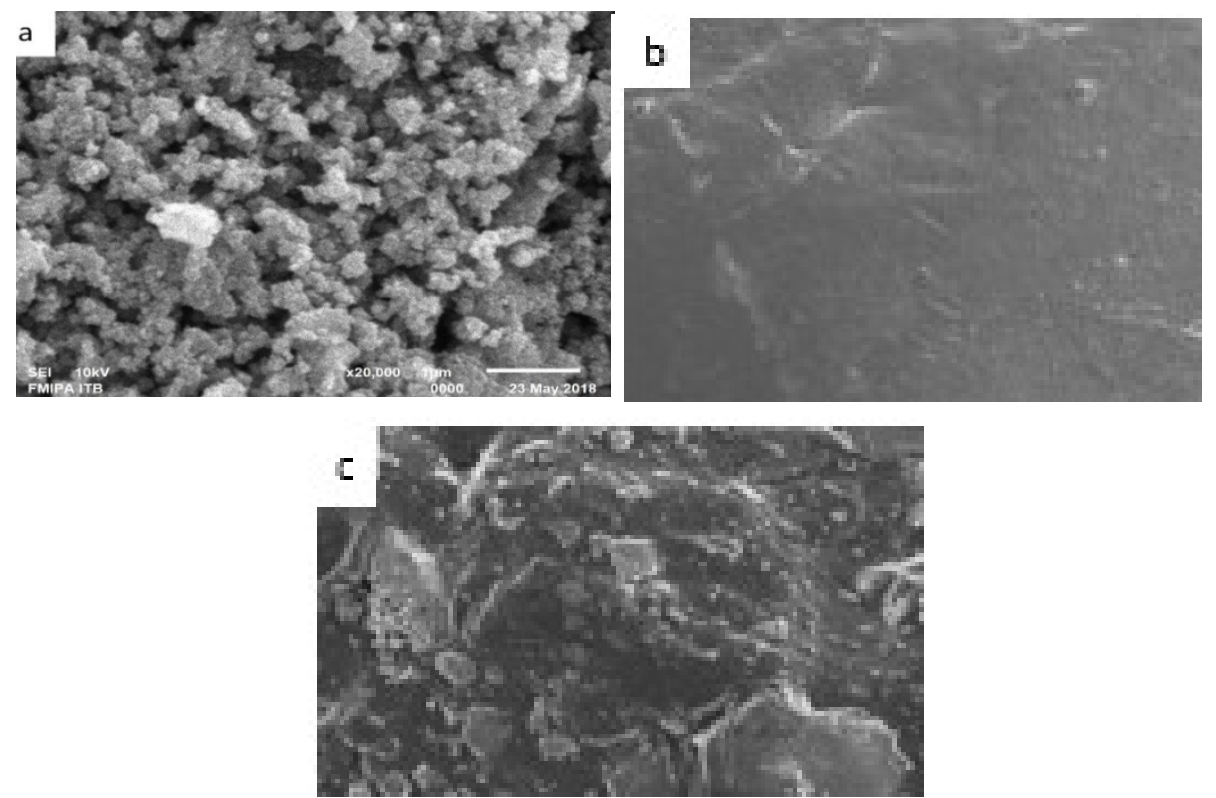

Fig.-1: SEM Images of (a) $\mathrm{Fe}_{3} \mathrm{O}_{4}$ Particle at x20.000 magnification, (b)Chitosan Microsphere at $\mathrm{x} 100$ magnification, (c)Sulfonated Magnetic Chitosan Crosslinked at x100 magnification

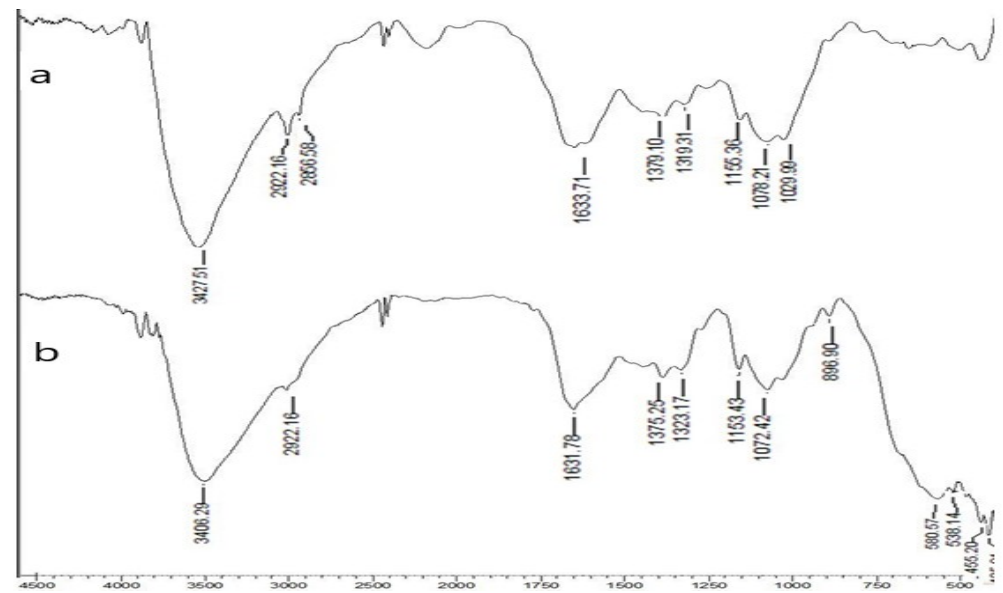

Fig.-2: FT-IR Spectra of (a) Chitosan without Modification, (B) Sulfonated Magnetic Cross-linked Chitosan 
RASĀYAN J. Chem.

Vol. 14 | No. 4 |2292-2297| October- December | 2021

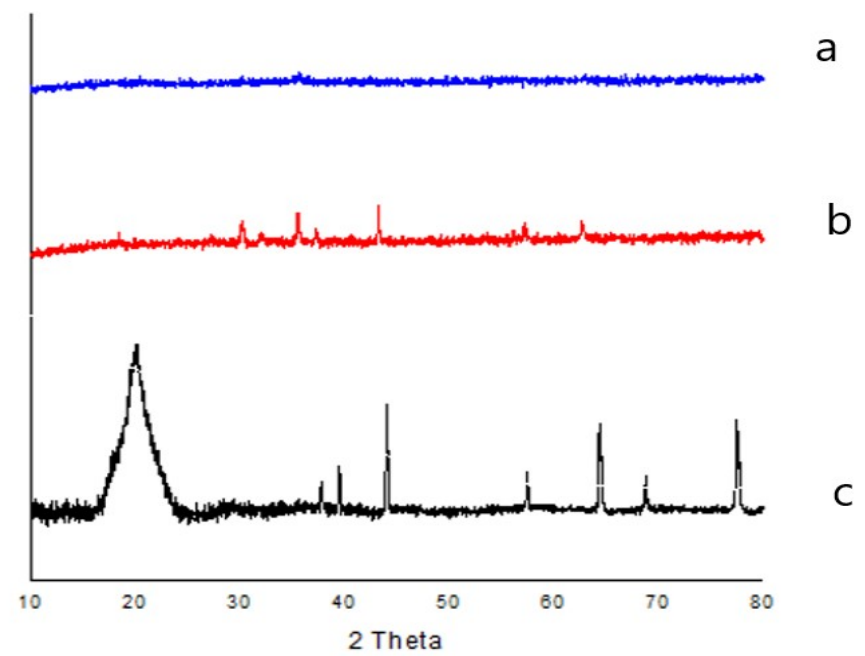

Fig.-3: The XRD patterns of (a) Modified Chitosan, (b) $\mathrm{Fe}_{3} \mathrm{O}_{4}$ and (C) Chitosan without modification.

\section{The Optimal Composition of Adsorbents}

In the preparation of sulfonated magnetic crosslinked chitosan, PEDGE composition has been varied from 0.05 to $0.09 \mathrm{~g}$ (Table 1). The addition of PEDGE can increase the adsorption capacity of the adsorbent. Nevertheless, the addition of PEDGE more than 0.09 decreases the adsorption performance. It is ascribed to the disabled binding sites of the chitosan, which were used for the formation of the crosslinking ${ }^{12,15}$.

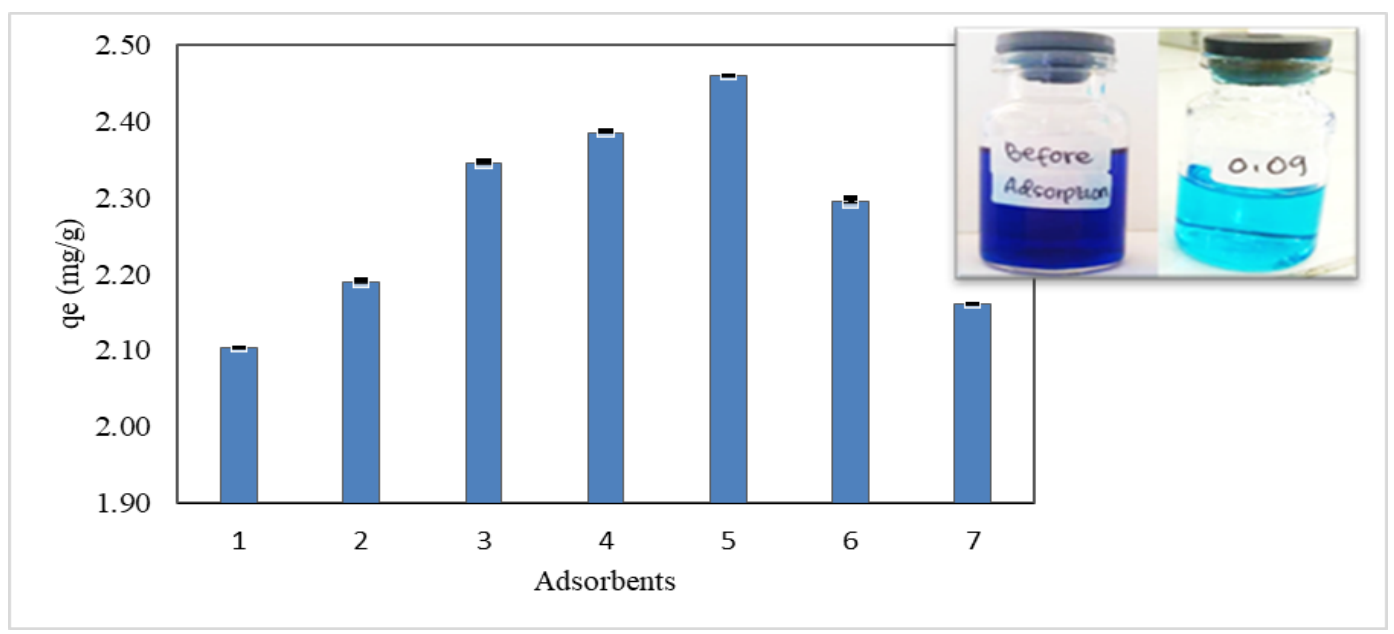

Fig.-4: The Adsorption Capacity of Adsorbents with Various Compositions

Table-1: Composition of Adsorbent

\begin{tabular}{c|c|c|c}
\hline \multirow{2}{*}{ Adsorbent } & \multicolumn{3}{|c}{ Composition $(\mathrm{g})$} \\
\cline { 2 - 4 } & Sulfonated Chitosan & $\mathrm{Fe}_{3} \mathrm{O}_{4}$ & PEDGE \\
\hline 1 & 0.25 & 0.5 & 0.05 \\
\hline 2 & 0.25 & 0.5 & 0.06 \\
\hline 3 & 0.25 & 0.5 & 0.07 \\
\hline 4 & 0.25 & 0.5 & 0.08 \\
\hline 5 & 0.25 & 0.5 & 0.09 \\
\hline 6 & 0.25 & 0.5 & 0.2 \\
\hline 7 & 0.25 & 0.5 & \\
\hline
\end{tabular}

Adsorption Isotherms Study

Adsorption isotherms are calculated based on the data obtained by varying the initial concentration of methylene blue (20-100 ppm). The adsorption was run using the batch method for 30 minutes. By 
adsorption isotherm studies, we can determine the amount of the maximum adsorption capacity. The isotherm Langmuir model can be obtained by plotting 1/Qe versus $1 / \mathrm{Ce}$. Langmuir's equation for the methylene blue adsorption on the sulfonated magnetic crosslinked chitosan is $\mathrm{y}=1.48 \mathrm{x}+0.035$ with $\mathrm{R}^{2}$ $=0.979$. The maximum adsorption capacity can be obtained (Qmax) from the following equation:

$$
\frac{1}{Q_{e}}=\frac{1}{Q_{n}}+\left(\frac{1}{b Q_{n}}\right)\left(\frac{1}{C_{e}}\right)
$$

Sulfonated magnetic crosslinked chitosan is $28.57 \mathrm{mg} / \mathrm{g}$.

Based on the Freundlich plot, the linear equation is $y=0.751 \mathrm{x}-0.094$ where $\mathrm{R}^{2}=0.940$. To obtain the value of Freundlich constants (Kf) and adsorption intensity (n), equation 2 was used.

$$
\ln Q e=\ln K f+\frac{I}{n} \ln C
$$

Based on the equation, the Freundlich constant value is 0.9102 with the adsorption intensity of 1.331 . The adsorption isotherm models explain that the adsorption in the research follows the Langmuir isotherm due to the higher coefficient of determination $\left(\mathrm{R}^{2}\right)$. Therefore, based on the assumption of the isotherm Langmuir, it can be concluded that the sulfonated magnetic crosslinked chitosan has homogeneous binding sites and monolayer adsorption.

Table-2: Isotherm Langmuir and Isotherm Freundlich Data

\begin{tabular}{c|c|c|c|c|c}
\hline \multicolumn{3}{c|}{ Isotherm Langmuir } & \multicolumn{3}{c}{ Isotherm Freundlich } \\
\hline $\mathrm{R}^{2}$ & $\begin{array}{c}\text { Qmax } \\
(\mathrm{mg} / \mathrm{g})\end{array}$ & $\mathrm{b}$ & $\mathrm{R}^{2}$ & $\begin{array}{c}\mathrm{Kf} \\
(\mathrm{mg} / \mathrm{g})\end{array}$ & $\mathrm{n}$ \\
\hline 0.979 & 28.57 & 0.025 & 0.940 & 0.9102 & 1.331 \\
\hline
\end{tabular}

\section{Regeneration Study}

The regeneration process was conducted to evaluate the extent to which the sulfonated magnetic crosslinked chitosan can be used repeatedly for methylene blue adsorption. The regeneration process was initiated with the desorption process by soaking the adsorbent in $\mathrm{H}_{2} \mathrm{SO}_{4} 3 \mathrm{M}$ for 30 minutes. Desorption is a process of the re-release of the adsorbed substances. Then, the adsorbent was separated from the methylene blue and washed with distilled water until neutral was reached and was ready to be reused. The results can be seen in Fig.-5.

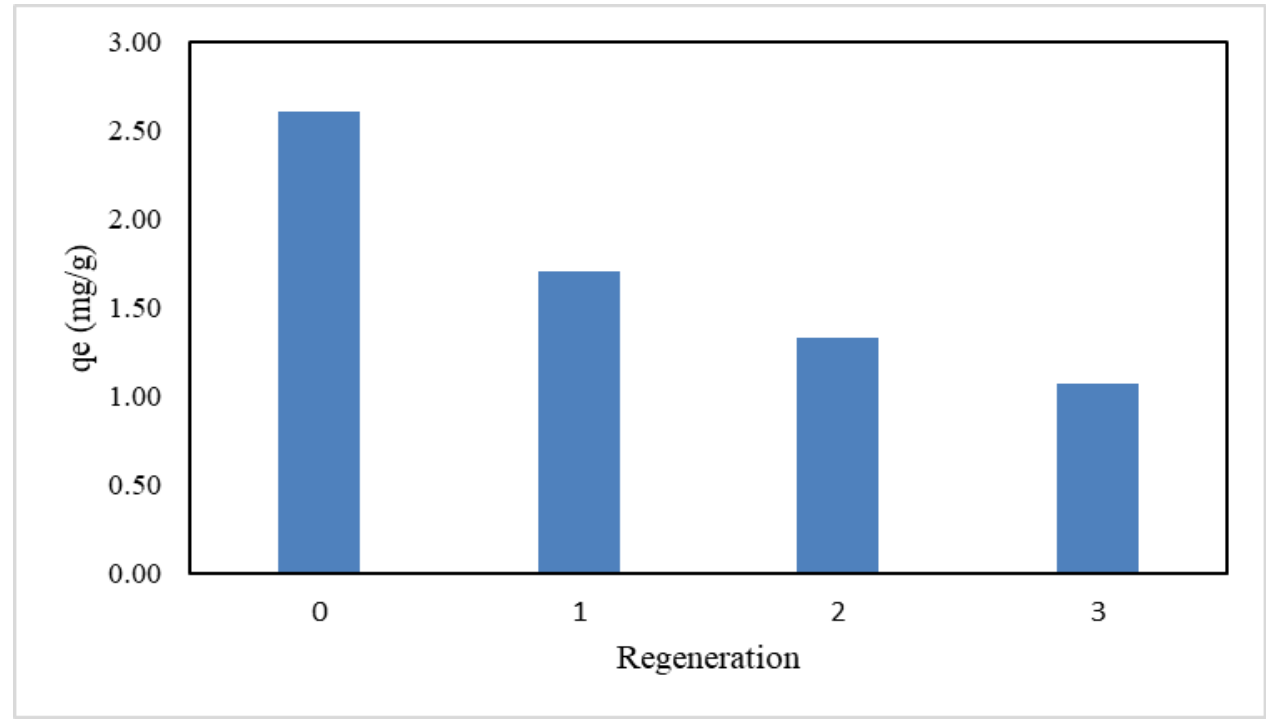

Fig.-5: The Regeneration of Sulfonated Magnetic Chitosan

The regeneration results of the sulfonated magnetic chitosan suggest the ability of the composites to be reused multiple times. Initially, the adsorption capacity is $2.604 \mathrm{mg} / \mathrm{g}$, and eventually decreases to 1.075 $\mathrm{mg} / \mathrm{g}$. The decreased adsorption capacity of the sulfonated magnetic crosslinked chitosan is equal to $58.717 \%$. 
RASĀYAN J. Chem.

Vol. 14 | No. 4 |2292-2297| October- December | 2021

\section{CONCLUSION}

Based on the results, it can be concluded that sulfonated magnetic crosslinked chitosan was successfully prepared and apply to methylene blue adsorption. The optimum composition of PEDGE in the preparation of sulfonated magnetic crosslinked chitosan is $0.09 \mathrm{~g}$. The methylene blue adsorption on the sulfonated magnetic crosslinked chitosan fits well to the Langmuir isotherm model $\left(\mathrm{R}^{2}=0.979\right)$ with an adsorption capacity of $28.57 \mathrm{mg} / \mathrm{g}$. The sulfonated magnetic crosslinked chitosan can be regenerated and reused multiple times use.

\section{ACKNOWLEDGMENT}

The author gratefully acknowledges the financial support from the Directorate General of Higher Education, Indonesia (DIKTI).

\section{REFERENCES}

1. H. Jayasantha Kumari, P. Krishnamoorthy, T. K. Arumugam, S. Radhakrishnan, and D. Vasudevan, International journal of biological macromolecules, 96, 324(2017), http://dx.doi.org/10.1016/j.ijbiomac.2016.11.077

2. I. M. Jauris, S. B. Fagan, M. A. Adebayo, and F. M. Machado, Computational and Theoretical Chemistry, 1076, 42(2016), http://dx.doi.org/10.1016/j.comptc.2015.11.021

3. M. Abbasi, Journal of Cleaner Production, 145, 105(2017), http://dx.doi.org/10.1016/j.jclepro.2017.01.046

4. A. Nawar, M. Ali, A. H. Khoja, A. Waqas, M. Anwar, M. Mahmood, Journal of Environmental Chemical Engineering, 9(1), 104871(2021), https://doi.org/10.1016/j.jece.2020.104871

5. A.M. Mohammad, A. Taher, E. Salah, A. H. Mohammad, E. E. A. Bahgat, Arabian Journal of Chemistry, 10(5) , 1878(2017), https://doi.org/10.1016/j.arabjc.2014.12.016

6. W. Zhao, X. Huang, Y. Wang, S. Sun, and C. Zhao, Carbohydrate Polymers, 150, 201(2016), http://dx.doi.org/10.1016/j.carbpol.2016.05.037

7. F. Rafiee and F. Rezaie Karder, International Journal of Biological Macromolecules, 146, 1124(2020), https://doi.org/10.1016/j.ijbiomac.2019.09.238

8. Rahmi, Lelifajri, R. Nurfatimah, Carbohydrate Polymers, 199, 499(2018), https://doi.org/10.1016/j.carbpol.2018.07.051

9. Y. Liu, P. Nie and F. Yu, Bioresource Technology, 320, B 124373(2021), https://doi.org/10.1016/j.biortech.2020.124373

10. H. Fathana, Rahmi, Susilawati, Ismaturrahmi and Nilawati, International Proceeding ASEAN YOUTH CONFERENCE 2018, https://doi.org/10.5281/zenodo. 2542977

11. N. Bukit, E. Frida, P. Simamora, and T. Sinaga, Chemistry and Materials Research, 7(7), 110(2015).

12. M. Nitsae, A.D.R. Madjid, L. Judge, A. Sabarurudin, Chemistry and Chemical Technology, 10(1) 2016, https://doi.org/10.23939/chcht10.01.105

13. S. Ika, S. Akhmad, Darjito, Chemistry Student Journal, 1(2), 175(2014).

14. H. Onem, H. Nadaroglu,. Journal of Food and Nutrition Research, 2(12), 938(2014), https://doi.org/10.12691/jfnr-2-12-13

15 Rahmi, Asian Journal of Chemistry, 28(10), 2267(2016), https://doi.org/10.14233/ajchem.2016.19966

[RJC-5944/2020] 